\title{
Gadgets and new educational technologies: real assistance or an obstacle?
}

\author{
Svetlana Alekseevna Molochkova, Marina Valentinovna Gromova, Valery Alekseevich \\ Bartenev $^{1}$, Aleksander Viktorovich Borodkin, and Aleksander Mikhailovich Salnikov
}

Financial University under the Government of the Russian Federation, Yaroslavl Branch, Department of Management and General Humanitarian Sciences, Yaroslavl, Russia

\begin{abstract}
The rapid spread of modern computer and communication technologies resulted in some global problems in society, including the adoption and rejection of such technologies in education. The COVID pandemic forced a widespread use of modern-style communications between tutors and students but unsolved problems still exist and will exist in the post-COVID era. The main goal of the paper is to find the potential borders of using modern technologies for students learning economics and business management in Russia. The authors conducted the survey in March of 2021 in the Yaroslavl Region, Russia. The main finding of the paper is the necessity of limiting the use of computer technology. The main reason for such limits is a possible decrease in students' health and the quality of education. All the results gained by the authors are applicable in the practice of organization of educational processes for students involved in economics and business management. Probably, the results may be inapplicable for students of other fields such as medicine, art, engineers, etc.
\end{abstract}

Keywords: distance learning, survey, higher education, technology implementation

\section{Introduction}

It is generally accepted that the Internet, electronic mail, and digital television took a significant part in people's lives. "The modern development of the society was marked by the rapid development of modern technologies", Yurov wrote in 2018 [1].

According to a survey kept by analytics of the online school "Skysmart" in 2020, traditional mass media move to the back stage of contemporary life, and teenagers are leading in the processes of refusing classic TV, radio, and printed media. According to the research results, all respondents spent at least 4 hours a day using their gadgets, primarily smartphones and tablets. Twenty-nine percent of the interviewed teenagers declared that they used gadgets for up to 6 hours a day. "Considering that the future of the Internet looks very promising and cloudless, it is obvious that the number of students who have modern communication devices will rapidly increase", the authors conclude [2, 3].

${ }^{1}$ Corresponding author: VABartenev@fa.ru 
Antony M. Townsend notices that the appearance of the World Wide Web in 1993 resulted in the cardinal change in human behavior. Another leading communication technology of the early 1990s was mobile phones. Both of them caused a transformation of reality perception and gave humankind brand new abilities to communicate worldwide regardless of distance [4]. Bringing the Internet to the top of communication technologies allowed people to find any information easily. Researchers denote the following advantages of using the Internet in education:

- $\quad$ obtaining the required information in an easy and fast way;

- comfortable visualization of the information;

- $\quad$ pre-programmed solving of problems and cases;

- $\quad$ interaction with the tutor any time the student needs;

- $\quad$ simplifying the control over educational results;

- $\quad$ instant access to libraries and storages of educational materials;

- $\quad$ ability to store huge volumes of textual and graphical information for educational purposes $[5,6]$.

On the other hand, theorists of education suspect that the widespread use of modern computer technologies in education may cause some global problems that cannot be solved right now. First of all, it is needed to develop a brand new paradigm of learning. Since gadgets have changed the lifestyle, all approaches to education should be changed too. Probably new ways of learning should use both synchronous and asynchronous communication between tutors and students, as well as increase the volume of work in virtual teams without direct tutor's supervision [7].

Another problem of implementing new technologies into educational processes concerns the readiness of tutors to use gadgets and communicate with students using the Internet. In fact, there are too many older tutors who resist any new things due to their age. It was too difficult for them to start using electronic mail two decades ago, and it is bigger trouble to start lecturing through video communication systems and review students' papers existing in electronic form only. Universities tried to re-learn their tutors for so-called "electronic education" but these attempts mostly have failed. On the other hand, new generations of tutors are ready for using modern educational technologies. According to some studies, one-third of interviewed tutors are ready to use any new way to learn their students [8].

The third problem found by researchers is the high differentiation in the availability of the high-speed Internet between urban and rural territories. This problem is not so relevant in European countries but it really becomes an unbreakable wall on the way to full electronic learning in ex-USSR countries. Most villages in Russia (especially in Siberia) are deprived of the ability to use an optical or wired connection to the Internet; mobile networks are unable to transmit data at the high speed needed for real-time face-to-face communication. This causes rural students to use asynchronous communication technologies only and probably decreases the quality of educational results [9].

The fourth major problem of using gadgets and new technologies in education concerns legal aspects. Some countries (e.g., Russia) have an education branch deeply regulated by public administration. Due to the full absence of regulation legislature, any modern electronic technologies are in the "grey area": they are not prohibited to be used and not allowed at the same time. Universities use them at their own risk. The "grey" status of new technologies brings up troubles related to academic fraud. Since testing is kept asynchronously without the direct supervision of a tutor, some students can use books, other materials during answering test questions or simply can find proper answers on the Internet. There are still no solutions to such problems $[10,11]$. 
So theorists of education and higher-school tutors came to the following conclusion. Electronic educational technologies appeared too recently to be studied properly. The COVID pandemic in 2020 forced the implementation of these technologies and it is not clear if it was implemented correctly or it was a life ring dropped to educational organizations to survive. Obviously, it is needed to deeply study all new technologies separated by their technological nature, as well as students' specializations [12]. It is more than likely that the results of such studies will reveal a large amount of ambiguities due to the high differentiation in the nature of learning for different professions. "Any innovation in education is a very controversial issue", concluded [13].

To answer the questions mentioned above for a specific university, the authors conducted a study. The main goal of the study was to decide are new technologies and gadgets suitable at the Financial University or not. The main goal determined the two particular tasks:

1. To determine the positive and negative influence of using modern computer technologies and gadgets on the educational processes in the fields of economics and business administration.

2. To determine students' attitudes toward using gadgets in learning.

\section{Methods}

The authors have created an electronic questionnaire to anonymously interview full-time students of the Yaroslavl branch of the Financial University. The questionnaire had six questions:

1. How frequently do you use gadgets (smartphones and/or tablets)? (The specific number of hours a day that the respondent spends using gadgets).

2. Did you increase or decrease the time spent using gadgets during the COVID pandemic in 2020? (The specific number of hours a day that respondents spent on gadgets during the pandemic).

3. Do you use gadgets for educational purposes after the COVID pandemic? (Answers are supposed to compare the intensity of using gadgets for educational purposes and for other ones).

4. What software/websites do (did) you use for educational purposes? (It is a semi-closed question; every answer is educational software/a website widely known in Russia).

5. Do you want to continue distance learning even if the COVID pandemic stops or do you prefer to learn in university classrooms? (Two available answers: "distance learning" or "classroom learning").

6. Why do you prefer distance learning or learning in classrooms? (It is semi-closed question that describes the most probable reasons to continue distant learning or return to the classroom; the respondent could type in his/her own reason).

To get results for future students that could enter the Financial University in 2021 and 2022, the authors expanded the survey and asked to answer the questionnaire under-graduate schoolchildren of a municipal school in the Myshkin town. The survey included 35 persons. According to the last census results, the population of the Yaroslavl Region aged 15-24 is 10,1509 persons. Assuming them as the universe, one can conclude that the survey has $\pm 12.17 \%$ error with $85 \%$ trust probability. Thus, the sample has a required and sufficient size and the survey is statistically justified. 


\section{$3 \quad$ Results}

The following results were obtained after processing the survey data.

As for the first question, the majority of respondents (more than half) answered that they used gadgets more than six hours per day (see Fig. 1). There were no schoolchildren and students who did not use gadgets. Only one respondent answered that he (or she) still used gadgets with the same intensity; others answered that the usage of gadgets increased (see Fig. 2). At the same time, the majority of interviewed persons declared that they began to spend less time on gadgets after the COVID pandemic and returning to classroom learning, and only one person answered that he (or she) increased the time spent on gadgets (see Fig. 3).

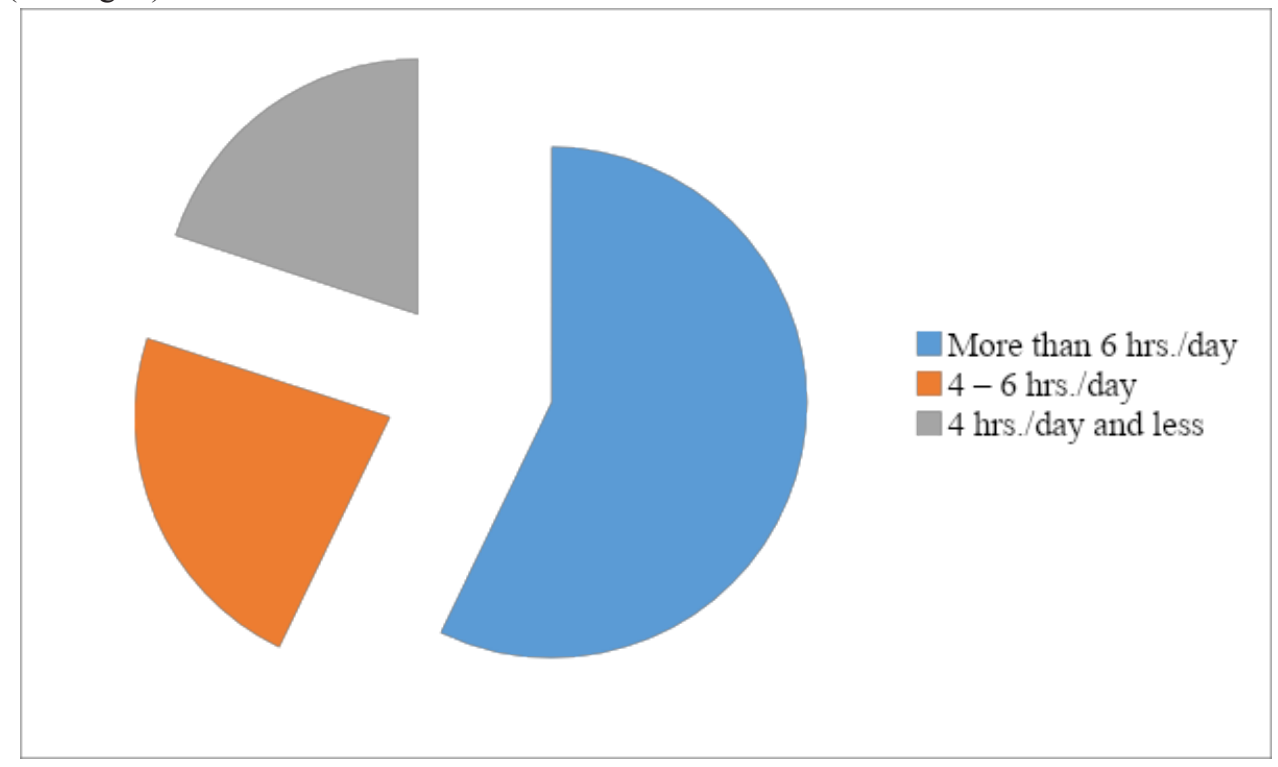

Fig. 1. Distribution of answers to the first question of the survey questionnaire: how frequently do you use gadgets? 


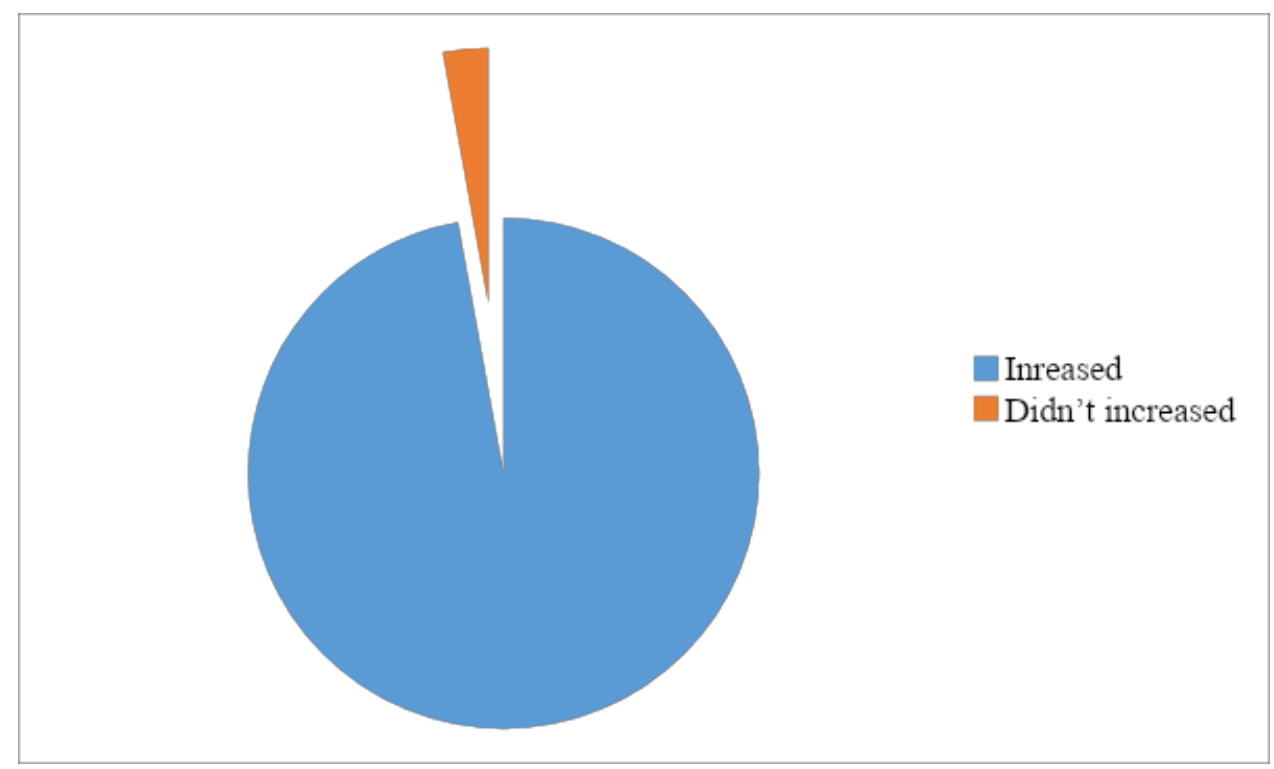

Fig. 2. Distribution of answers to the second question of the survey questionnaire: Did you increase or decrease the time spent using gadgets during the COVID pandemic in 2020 ?

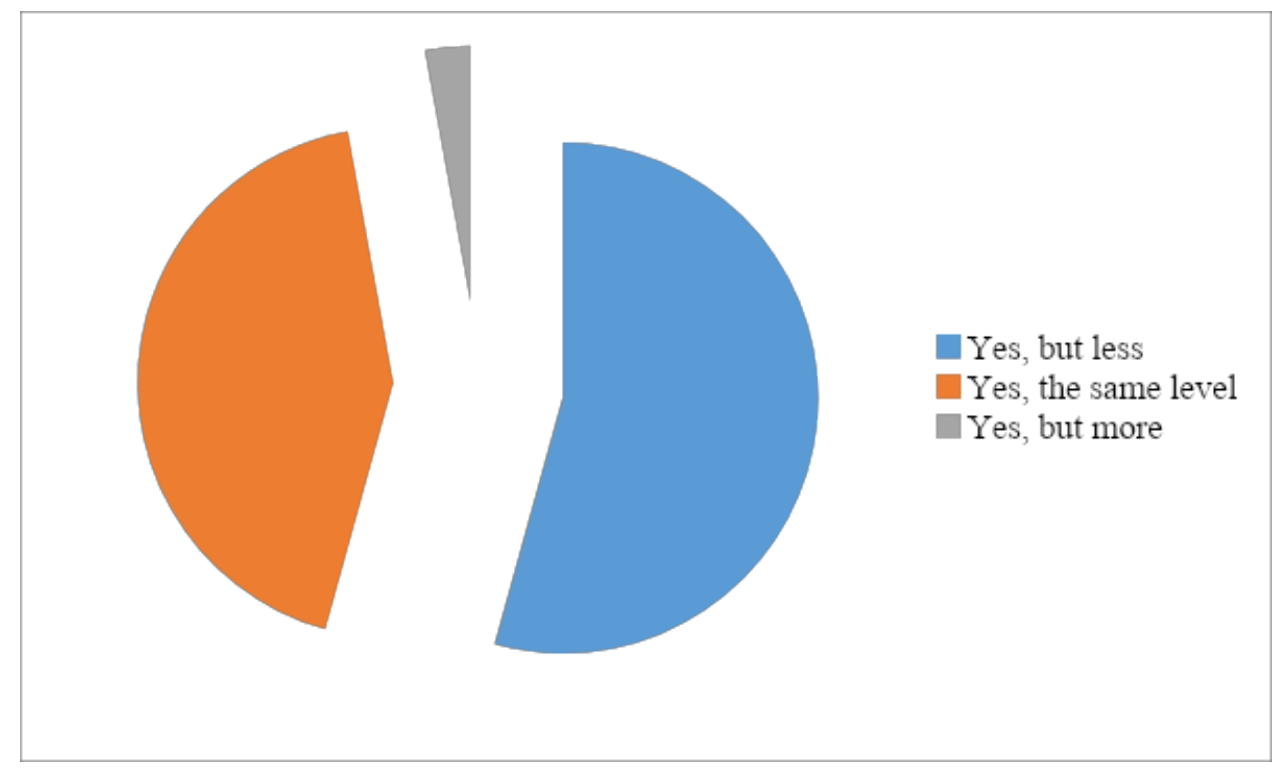

Fig. 3. Distribution of answers to the third question of the survey questionnaire: Do you use gadgets for educational purposes after the COVID pandemic?

The fourth question gave the rating of software and web services that were used during the COVID pandemic (see Fig. 4). Electronic mail, the oldest communication technology, took the first place. Discord and the FU portal - the technologies that have been chosen at the Yaroslavl branch of the Financial University took the second place. The Regional Diary and Yaclass, services intended for use at schools, not at universities, took the third place. Besides, $11.43 \%$ of respondents answered that they used something else, e.g. VKontakte, the most popular social network in Russia and some ex-USSR countries. 


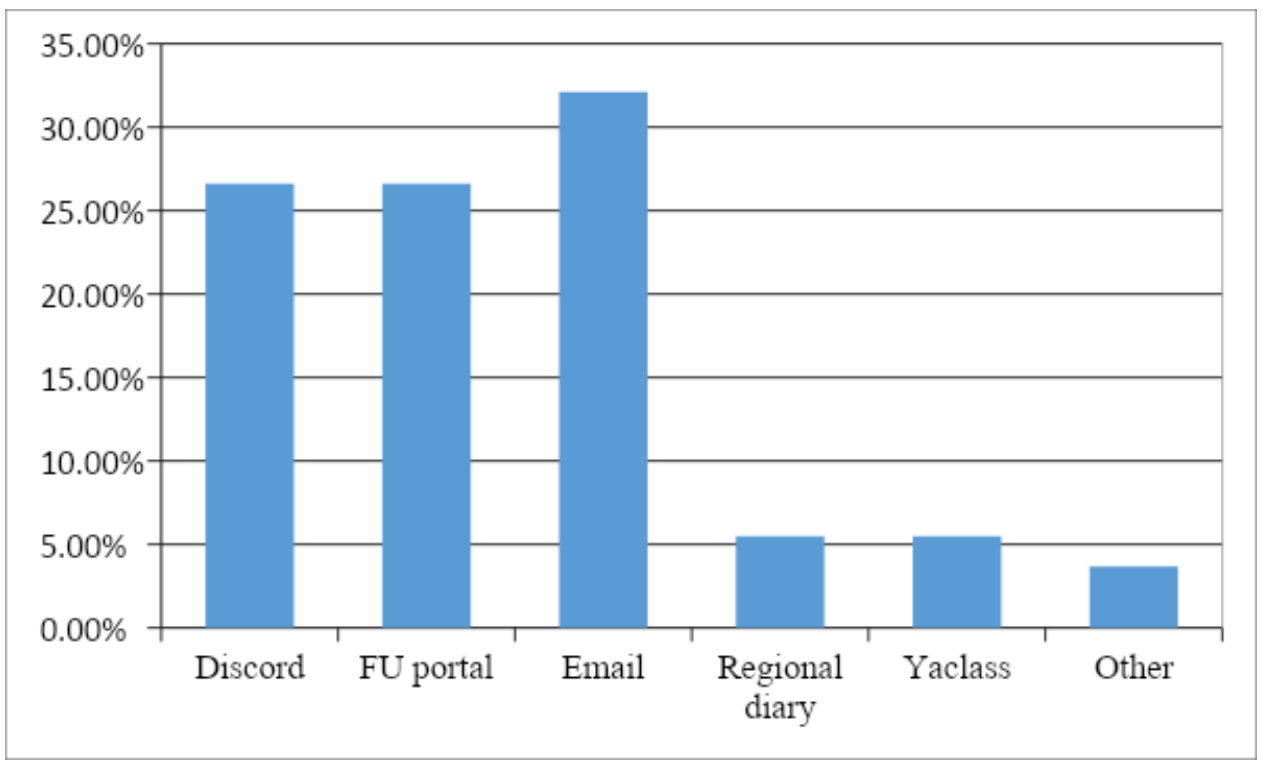

Fig. 4. Distribution of answers to the fourth question of the survey questionnaire: What software/websites do (did) you use for educational purposes?

Answers to the fifth and sixth questions were surprising (see Fig. 5). More than $71 \%$ of students wanted to return to classroom learning instead of continuing with distant classes. Everyone had at least two reasons why he/she wanted it.

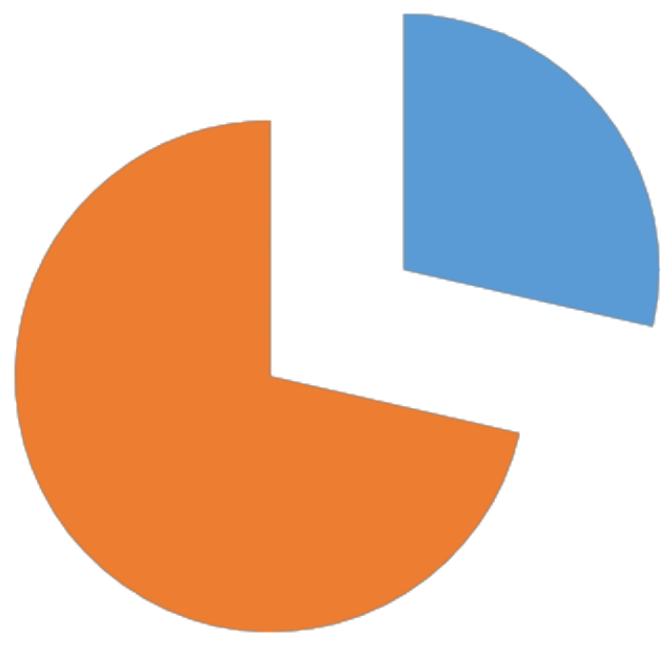

Distant learning

Learning in classrooms

Fig. 5. Distribution of answers to the fifth question of the survey questionnaire: Do you want to continue distance learning even if the COVID pandemic stops or do you prefer to learn in university classrooms?

In general, the survey was kept perfectly. There were no compulsions to take part in the survey or any compulsion to choose specific answers, so one can assume that the respondents really expressed their will and opinion. 


\section{Discussion}

The survey showed that most teenagers and students in the Yaroslavl Region spent more than six hours a day with gadgets. It is more than the mean value in Russia. This result could be explained by the proximity of the Yaroslavl Region to the Moscow city and the high availability of mobile networks even in rural lands. The same explanation could be applied to answers to the second question. On the one hand, one can conclude that the Yaroslavl Region is a leading territory and local universities and schools probably will not face technical troubles on students' side during the total implementation of distant electronic learning. On the other hand, spending more than six hours a day with a computer or gadget is a very bad result from a medical point of view. One can assume that this enormous use of gadgets will lead to a massive decrease in the health of the generation born about 2000 .

The same conclusion can be made after analyzing answers to the third question. Traditional schoolchildren's or students' schedule assumes classes from 8:30 a.m. to 3:00 p.m., amateur sport or art activities after classes and execution of home assignments in the evening without electronic learning technologies. During the COVID pandemic, schoolchildren and students were deprived of physical activities; all day between bed-times was dedicated to electronic learning. It was one of the negative consequences of the COVID pandemic, and it is obvious that implementing new computer technologies into education during the post-COVID era must be limited by the time spent with computers or gadgets [14].

Answers to the fourth question did not bring any unexpected results. Schoolchildren and students were forced to use software and websites chosen by educational organizations. Moving to distance learning in March of 2020 was so fast, and there was no time to discuss with students the software they prefer. System administrators were forced to recommend tutors the software and services that could be used on the majority of devices. In the future, the question of software and web service potentially could become one of the key questions. It is obvious that software must be comfortable to use and able to be run on a variety of devices to ensure high-quality results of education; students and tutors should not solve technical difficulties instead of the learning process $[15,16]$.

The fifth and sixth questions gave unexpected survey results. Based on the high level of gadget use, it could be assumed that students prefer to study electronically without a presence in classrooms. However, the reality is quite another. Students want to use gadgets for common purposes (communicate between themselves, obtain news, get fun, and so on), but they do not want to use computers and gadgets for education. They prefer to learn in classrooms with limited use of electronic learning technologies. The main benefits of learning in classrooms noted by students are:

1. Face-to-face communication between students and tutors.

2. A higher level of the skills obtained in the classroom with the tutor's assistance rather than those obtained during distance learning.

3. Stable conditions of classroom learning (including schedule, deadlines, etc.).

4. Internet outages during online classes that may result in a low level of understanding some topics or home assignments.

5. Most of older tutors are unable to communicate with students through video communication services, to process and rate home and class assignments written electronically. 
The minority of students who preferred distance learning could explain their choice by comfortable conditions at home and saving time to get to the campus (due to high traffic jams in Yaroslavl, students and tutors spend up to 3 hours a day to get to campus and back by the municipal transportation system). The same results have been obtained by other studies in different countries [17-22].

Based on the result mentioned above, the Yaroslavl branch of the Financial University decided to recover classroom learning with the restricted use of distance learning. The problem of implementing the new educational technologies is too versatile to be solved in a year. Each of the participants in the learning process has reasons to use new technologies or decline them; there is and will be no universal solution that satisfies everyone. Also, it should be kept in mind that educational processes in other fields rather than economics and business administration (e.g., medicine, engineering, art) could have peculiarities not mentioned in this study; the results of a similar survey of the students could be completely different $[23,24]$.

\section{Conclusion}

Summarizing the study results, one can conclude that total moving to distant electronic-based technologies is inappropriate in current economic, social, and technological conditions. Such transformation of educational processes can result in a significant decrease in students' health, as well as a decrease in the quality of education. Another negative consequence that could be met after electronization of the educational process is an increase in the number of unsatisfied students.

Nowadays, a lot of problems of electronic education are still unsolved. These problems are related to insufficient learning materials, the low-level skills of tutors and the probable impossibility to teach students in some specific fields. Gradual solving of such problems will allow spreading new educational technologies more and more but it is suspected that the process will be stretched for years and years.

\section{References}

1. I.A. Yurov, Young Sci, 1(15), 101-106 (2018)

2. A. Balandina, "Sidyat ponikshie": pedagogi o problemakh obucheniya onlain ["Sitting drooping": teachers about learning problems online]. Accessed on: October 1, 2021. [Online]. Available: https://www.gazeta.ru/social/2020/08/24/13208521.shtml

3. Ya.S. Medvedeva, Young Sci, 15(119), 473-476 (2016)

4. A.M. Townsend, J Urban Techn, 7(2), 85-104 (2000). https://doi.org/10.1080/713684114

5. A.V. Tatarintsev, Young Sci, 25(211), 317-319 (2018)

6. X. Chen, D. Zou, H.Xie, G. Cheng, Edu Tech Soc, 24(1), 205-222 (2021)

7. R.M. Mukhamadeeva, Euroasian Sci Union, 2-1(48), 57-59 (2019)

8. E.A. Shefer, Young Sci, 16(358), 22-25 (2021)

9. I.S. Kargopolov, Young Sci, 12(250), 268-269 (2019)

10. T.F. Kryaklina, Econ. Prof. Bus, 2(2), 77-82 (2016)

11. Z.Z. Kodirov, Young Sci, 15(149), 585-586 (2017)

12. N.P. Kiselev, Young Sci, 4(346), 340-344 (2021) 
13. M.Sh. Bozorova, Int J Human Nat Sci, 2, 39-41 (2018)

14. O.N. Ragozin, et al., Bul Nizhnevartovsk State Univ, 2, 130-135 (2020). https://doi.org/10.36906/2311-4444/20-2/17

15. A. Ellahi, Edu Techn Soc, 21(4), 64-75 (2018)

16. Ch.K. Siu, Edu Techn Soc, 22(1), 28-43 (2019)

17. G.G. Karhanyan, Cross-Cult Stud: Edu Sci, 5(2), 92-96 (2020). https://doi.org/10.24411/2470-1262-2020-10080

18. N. Guzachchova, Bul Sci Prac, 6(5), 457-460 (2020)

19. F. Manganello, C. Falsetti, T. Leo, Edu Techn Soc, 22(1), 44-58 (2019)

20. N.L. Schroeder, Edu Techn Soc, 20(4), 138-147 (2017)

21. J. Zilvinskis, A.A. Masseria, G.R. Pike, Res Higher Edu, 58(8), 880-903 (2017). https://doi.org/10.1007/s11162-017-9450-6

22. M. El-Masri, A. Tarhini, Edu Techn Res Devel, 65, 743-763 (2017). https://doi.org/10.1007/s11423-016-9508-8

23. I.S. Grigoriev, S.A. Belyaev, Software J: Theory App, 1, 2 (2020)

24. A.M. Tokesheva, et al., Sci Healthcare, 22(6), 80-85 (2020) 